\title{
A Study on the Influence of Agricultural Insurance on the Upgrading and Optimization of Agricultural Industrial Structure in China -- An Empirical Analysis Based on GMM Model of Panel System
}

\author{
Li Xiang ${ }^{1, a}$, Liu Yining ${ }^{2, b}$, Zhao Rudan ${ }^{3, c}$ \\ ${ }^{123}$ College of Economics and Management, China Agricultural University, Beijing, 100083, China
}

\begin{abstract}
This article uses panel data from 2000 to 2019 in the China Insurance Yearbook, China Rural Statistical Yearbook and the National Bureau of Statistics. Based on the system generalized moment estimation model, the influence of the density and depth of agricultural insurance at the regional level on the upgrading and optimization of agricultural industrial structure is studied. The empirical results show that the increase in the depth of agricultural insurance has a significant role in promoting the upgrading of the agricultural industry structure. The increase in the density of agricultural insurance has a certain inhibitory effect on the structure of the agricultural industry. Therefore, it needs to improve the agricultural insurance financial subsidy policy, guide the diversified development of agricultural insurance, and establish an agricultural risk reinsurance mechanism to escort the upgrading and optimization of the agricultural industry structure.
\end{abstract}

\section{Introduction}

The 19th National Congress of the Communist Party of China proposed that socialism with Chinese characteristics has entered a new era, and the Chinese economy has shifted from a stage of rapid growth to a stage of high-quality development. As China's agriculture enters a new stage of high-quality development, the main contradiction it faces has changed from insufficient total to structural contradictions. Structural contradictions have become increasingly prominent, and there is an urgent need to optimize the structure of the agricultural industry. After several stages of adjustments, the structure of agricultural industry has gradually shifted from a single planting industry to the comprehensive development of the five major agricultural industries of agriculture, forestry, animal husbandry, fishery and agriculture, forestry, animal husbandry and fishery services. The agricultural industry structure has undergone profound changes and great achievements have been made. However, the agricultural risks faced in this process have become increasingly prominent. In the absence of guarantees, farmers themselves cannot bear the huge economic losses caused by the agricultural risks in the process of upgrading the agricultural industrial structure, which in turn discourages their enthusiasm to actively optimize the agricultural industrial structure. The existence of agricultural insurance will affect the risk appetite of farmers, and guide them to plant higher risk economic crops as one of the tools of market-oriented agricultural risk management. Agricultural insurance plays an important role in the upgrading and optimization of the agricultural industry structure due to its functions such as risk dispersion, disaster prevention and loss prevention, and loss compensation. Agricultural insurance can promote the upgrading and optimization of the agricultural industry structure through mechanisms such as increasing the supply of agricultural credit and promoting the advancement of agricultural technology

Based on the above analysis, agricultural risk is a prominent problem faced in the process of upgrading the agricultural industrial structure. The main purpose of agricultural insurance is to diversify and transfer agricultural risks. As an important tool for agricultural risk management, how does the rapid development of agricultural insurance affect the upgrading of the agricultural industry structure? Can it play a role in promoting the upgrading of the agricultural industry structure? These issues are worthy of in-depth discussion. Based on the above considerations, this article uses the macro data of China Insurance Yearbook and China Rural Statistical Yearbook Database 2000-2019 to study the impact of agricultural insurance on the upgrading and optimization of agricultural industrial structure. Compared with the existing literature, the possible innovations of this article are as follows: (1) From the two latitudes of agricultural insurance density and agricultural insurance depth, conduct empirical tests on the direction and strength of agricultural insurance's

à2018311250304@cau.edu.cn, b743670354@qq.com, c'zrd993319746@163.com 
influence on the upgrading of agricultural industrial structure. (2) Taking into account the interaction between agricultural insurance and agricultural industrial structure, this paper innovatively uses the systematic GMM model to deal with endogenous issues.

\section{Literature review}

The research on the relationship between agricultural insurance and the upgrading of agricultural industrial structure originated from the research on the relationship between agricultural insurance and agricultural economic growth. With the continuous deepening of related research, agricultural insurance and the upgrading of agricultural industrial structure, as one of the important branches, have attracted the attention of more and more scholars at home and abroad.

Foreign scholars hold different views on the relationship between agricultural insurance and agricultural industrial structure adjustment. Some scholars believe that agricultural insurance will play a positive role in the adjustment of agricultural production structure. Turvey (1992) first found that agricultural insurance financial subsidies would encourage farmers to increase the production of high-risk crops, which in turn would trigger the adjustment of agricultural production structure ${ }^{[1]}$. Wu (1999) studied the impact of crop insurance on crop mix in central Nebraska and found that providing corn insurance will transfer land from hay and pasture to corn, which will affect the production structure [2]. Wu and Adams (2001) found that income insurance can change the way crops are grown ${ }^{[3]}$. Glauber and Collins (2002) further analyzed from the perspective of differentiated agricultural insurance premium subsidy policies. It is believed that the difference in the proportion of agricultural insurance premium subsidies will cause the impact of the crop production structure, thereby affecting the production structure in the agricultural industry structure ${ }^{[4]}$. Coleman and Shaik (2009) based on the empirical research of North Dakota [5], and Tronstad and Bool (2010) using US county-level panel data ${ }^{[6]}$ also support the views of Glauber and Collins (2002). Yu and others (2018) conducted an empirical analysis of annual data on major crops in the United States and found that crop insurance premium subsidies affect crop planting areas through direct profit effects and indirect coverage effects, which in turn affect the structure of the agricultural industry ${ }^{[7]}$. However, some scholars have expressed doubts about this view. Goodwin (2004) conducted an empirical analysis on the corn and soybean yields in the corn belt of the Midwestern United States and wheat and barley in the Northern Great Plains by constructing a multi-equation structure model and found that agricultural insurance premium subsidies did not significantly change the insured crops. Planting area, its impact on the structure of agricultural production is not obvious ${ }^{[8]}$. Young (2001) analyzed relevant data on crop production areas in the United States through a national policy simulation model and found that only a small number of crops (wheat and cotton) planted areas and yields have increased. However, due to the lack of elasticity of the demand for major crops, overall crop insurance has no significant impact on the structure of agricultural production ${ }^{[9]}$.

Domestic scholars are also more concerned about the issue of agricultural insurance and the upgrading of agricultural industrial structure. Many scholars have conducted research on this from a theoretical and empirical perspective. In theory, scholars such as Yang Ruizhen (2002), Li Linjie, Gu Liubao (2003) and Chen Juncong (2016) believe that agriculture is a high-risk industry due to its high dependence on natural conditions. Moreover, the occurrence of its risks is more uncontrollable and destructive. A sound agricultural insurance mechanism can effectively prevent and resolve the risk factors faced in the process of agricultural industrial restructuring, so as to ensure the smooth advancement of agricultural industrial restructuring. Therefore, more emphasis is placed on the risk management role of agricultural insurance ${ }^{[10]}$. Qiu Shizhong (2005), Tian Li (2012), Zhang Xiaodong and Sun Rong (2015) emphasize the policy insurance function of agricultural insurance, and believe that differentiated premium subsidy policies can affect farmers' planting decisions and increase farmers' input and output levels and speed up the upgrading of industrial structure ${ }^{[11]}$. From the results of empirical research, there are relatively few domestic researches in related fields, and the research results of different scholars are not the same. Xie Xiaofeng (2016) established a partial least squares regression model based on agricultural data in Guangdong from 2000 to 2014 and found that rural insurance services are an important factor in promoting farmers' income and accelerating the transformation of the industrial structure, and there is a harvest paradox and the phenomenon of low grain hurts farmers ${ }^{[12]}$. However, Wen Hongfei (2016) used the cointegration test to study the time series data of Linyi City, Shandong Province from 2000 to 2014 and found that the impact of agricultural insurance on the adjustment of agricultural production structure was not significant ${ }^{[13]}$.

To sum up, domestic and foreign researchers have demonstrated the relationship between agricultural insurance and the upgrading of agricultural industrial structure from different perspectives, which has laid a theoretical and empirical foundation for this study. However, there are few empirical studies from the perspective of risk management, and there is also a lack of regional heterogeneity discussion. Based on the above considerations, this paper constructs a generalized moment estimation dynamic panel model, and comprehensively uses China Insurance Yearbook, China Rural Statistical Yearbook and the database of National Bureau of Statistics to demonstrate the impact of agricultural insurance on the upgrading of industrial structure, in order to provide a useful supplement to the existing research. 


\section{Model setting and measurement method}

\subsection{Reference econometric model}

The upgrading of agricultural industrial structure is a process of dynamic evolution with time persistence. Therefore, in order to more accurately investigate the impact of agricultural insurance on the upgrading of agricultural industrial structure, the explanatory variables of the explained variables in this paper should be introduced into the model setting, and the dynamic panel model should be adopted to control the possible dynamic effects in the model. Based on previous literature, the following benchmark measurement model is set.

$$
y h_{i t}=\alpha_{0}+\alpha_{1} y h_{i, t-1}+\alpha_{2} m d_{i, t}+\alpha_{3} d e p_{i t}+\alpha_{4} X_{i t}+\mu_{i}+\varepsilon_{i t}
$$

Among them, $i$ and $t$ represent province and year. Explained variable $y h$ is an index reflecting the optimization of agricultural industrial structure upgrading in various provinces. This paper refers to Kuang (2016)' $\mathrm{s}$ method of calculating the optimization index of agricultural industrial structure through the two dimensions of industrial structure rationalization and industrial structure altimization ${ }^{[14]}$. The agricultural industrial structure optimization index is used to measure the agricultural industrial structure optimization index weighted by the calculated agricultural industrial structure advanced index and the agricultural industrial structure rationalization index. $y h_{i, t-1}$ is a first-order lag term for the explained variable. Core explanatory variables

$m d$ and dep reflect the density and depth of agricultural insurance in each province. ${ }{ }_{i t}$ refers to a set of other control variables that affect the upgrading of agricultural industrial structure. $\mu_{i}$ and $\varepsilon_{i t}$ refer to the individual heterogeneity intercept term and random disturbance term, and the natural logarithm of all variables in this paper is taken to weaken the possible heteroscedasticity problem.

\subsection{Selection of measurement method}

As the explanatory variables of the dynamic panel model are added with a lag period of the explained variables, endogeneity will arise. In this case, the estimation method applicable to the static panel model will be used for estimation, and the estimation results obtained will be biased and inconsistent. In order to overcome the endogeneity problem and obtain consistent estimation, there are mainly two estimation methods for dynamic panel models. One is the differential GMM proposed by Arelelano and Bond (1991). The other is the system GMM proposed by Blundell and Bond (1998).

Differential GMM is to solve the endogenous problem and make difference to the original equation, using variable lag order as the instrumental variable. The disadvantage is that the individual effects of the non-observed cross-section and other variables that do not change with time are eliminated during the difference and sometimes the lag order of the variable is not an ideal instrumental variable. The system GMM is equivalent to combining the difference equation and the original level equation, using the variable lag order as the instrumental variable of the difference equation. At the same time, using the lag term of the differential variable as the instrumental variable of the level equation is an extension of the differential GMM, which can overcome the problem of weak instrumental variables in the differential GMM estimation. Thereby reducing the bias of the estimator and improving the estimation efficiency, so it has a better limited sample (Blundell \& Bond, 1998). In view of this, this article uses the system GMM. When using the system GMM to estimate the dynamic panel model, sequence correlation test and Sargan test are required to judge the applicability of the system GMM. Among them, the serial correlation test is used to test whether the disturbance item has a second-order serial correlation, and the Sargan test is used to judge whether all the instrumental variables used in the model estimation are valid.

\section{Variable selection and data source}

\subsection{Variable selection}

Limited to the availability and accuracy of data, combined with existing related research results, this article uses the agricultural industry structure optimization index of 31 provinces from 2010 to 2019 as the explained variable, and chooses agricultural insurance depth and agricultural insurance density as the core. The explanatory variables include the level of economic development, the aging of the rural population, the level of urbanization, rural human capital, financial expenditure on agriculture, and agricultural fixed asset investment as the control variables. The specific variables are explained as follows.

\subsubsection{Explained variable}

The optimization of the agricultural industry structure refers to the process of re-optimizing the allocation of agricultural resources among various agricultural industries, and then continuously improving the level and efficiency of the agricultural industry structure, including two dimensions of structural rationalization and structural advancement. This paper draws on the method of Kuang Yuanpei and Zhou Ling (2016) to calculate the optimization index of agricultural industry structure, and the corresponding calculation formula is as follows.

$$
y h=0.05^{*} h l h+0.05^{*} g j h
$$

In equation (1), hlh is the rationalization index of industrial structure, which refers to the reflection of the coupling degree of factor input and output structure. The index is introduced here to measure, which not only 
considers the relative importance of the industry but avoids the calculation of absolute value, and retains the theoretical basis and economic meaning of structural deviation degree. The corresponding calculation formula is as follows.

$$
h l h=\sum_{i=1}^{n} \frac{y_{i}}{y} \ln \left(\frac{y_{i}}{l_{i}} / \frac{y}{l}\right)
$$

$$
\underline{y_{i}}
$$

Among them, $y$ is expressed by the proportion of the output value of agriculture, forestry, animal husbandry and fishery industries to the total agricultural output value. $\frac{y}{l}$ reflects production efficiency. $\underline{y_{i}}$ represents the productivity of an industry, based on $\overline{l_{i}}$

the availability of data, measured here in terms of agricultural, forest, pastoral, fishery value added/intermediate consumption. The productivity of an industry, based on the availability of data, is measured here by the added value/intermediate consumption of agriculture, forestry, animal husbandry and fisheries. The advanced industrial structure is based on the rational industrial structure. It refers to the process in which the focus of economic development or industrial structure shifts from the primary industry to the secondary industry and the tertiary industry. In this paper, by referring to the methods of Liu Wei (2008), Kuang Yuanpeng and Zhou Ling (2016) to measure the industrial structure elevation. The index of industrial structure elevation is constructed as follows.

$$
g j h=\sum v_{i t}^{*} l p_{i t}
$$

$v_{i t}$ is the proportion of $t$ the output value of the industry in time ${ }^{i}{ }^{l} l p_{i t}$ is the labor productivity of the industry $i_{\text {in time }} t$. Similarly, the value added realized by unit consumption is expressed in terms of the proportion of industry output to total agricultural

output $v_{i}$. At the same time, this paper-maximum standardization method is used to standardize the labor productivity index. The formula is as follows:

$$
l p_{i t}^{n}=\frac{l p_{i t}-\max \left(l p_{i t}\right)}{\max \left(l p_{i t}\right)-\min \left(l p_{i t}\right)}
$$

\subsubsection{Core explanatory variable}

Agricultural insurance density ( $m d$ ) refers that the density of agricultural insurance not only reflects the development degree of agricultural insurance business in a certain area, but also reflects the public's cognition of agricultural insurance. Here to each province last year per capita agricultural premium income takes logarithm.

Agricultural insurance depth ( $d e p$ ) refers that agricultural insurance depth is a commonly used index to measure the development level of agricultural insurance, which refers to the proportion of agricultural insurance premium income to agricultural GDP output value in various provinces. This index can not only reflect the scale of agricultural insurance market, but also integrate the level of regional agricultural development, and highlight the actual level of agricultural insurance development in various regions. At the same time, in order to smooth the index, the proportion of insurance premium income to agricultural GDP output value is logarithmic here.

\subsubsection{Controlled variable}

Fiscal expenditure on agriculture ( $f e e$ ) refers that financial support for agriculture is an important means for the state to support the development of rural production, mainly manifested in the preferential policy of capital investment. It can promote the rational allocation of factors of production among various industries of agriculture, forestry, animal husbandry and fishery, and speed up the pace of upgrading the agricultural industrial structure. In this paper, the ratio of agricultural and forestry water affairs expenditure to the total rural population in the province is used to measure the expenditure of supporting agriculture, and the natural logarithm is used to deal with it.

Level of economic development ( $g d p$ ) refers that regional GDP is often recognized as the best index to measure the economic situation of a country or region, which reflects the economic strength and market scale of a country (or region). The high quality development of economy has created a good environment for the upgrading and transformation of industrial structure.

Level of urbanization ( urban ) refers that urbanization and industrial structure upgrading influence and interact with each other. Urbanization promotes industrial structure upgrading by influencing regional economic development level and material capital, while industrial structure upgrading promotes urbanization development by influencing market factors, human capital, technological progress and other factors (Wang Fang. 2020 ${ }^{[15]}$. In this paper, the urbanization level is measured by the ratio of the urban population to the total population of each province at the end of the year, namely, the urbanization rate, and the natural logarithm is taken.

Investment in agricultural fixed assets ( $f i x$ ) refers that investment in agricultural fixed assets is the material basis of promoting the upgrading of agricultural industrial structure. The change of agricultural fixed assets investment structure, policy and emphasis has an important influence on a series of changes, such as the restructuring of agricultural industrial structure, the optimization of industrial layout, the upgrading of technology and equipment, and the updating of knowledge and skills of employees. In this paper, fixed asset investment in agriculture, forestry, animal husbandry and fishery of each province is adopted to measure agricultural fixed asset investment (Zhang 
Jianjun and Zhao Qilan, 2017), and natural logarithm processing is taken for it.

Ageing of rural population ( old ) refers that population aging mainly responds to the rising labor cost by increasing consumer demand, accelerating the accumulation of human capital and forcing enterprises to replace labor with capital and technology, which promotes the upgrading of industrial structure (Wang Wei. 2015). In this paper, the aging rate of rural population is adopted to measure the aging rate of rural population, which is equal to the ratio of the number of people aged 65 or above in rural areas of each province to the total rural population of the province, and the natural logarithm is taken.

\subsection{Data Sources}

The data involved in the article mainly come from the 2010-2019 China Rural Statistical Yearbook, China Insurance Yearbook and the National Bureau of Statistics database. Among them, the output value, added value and intermediate consumption of agriculture, forestry, animal husbandry and fishery are from the China Rural Statistical Yearbook. Agricultural insurance premium income and compensation expenditures come from the China Insurance Yearbook. The total regional population, rural population, urban population, rural population aged 65 and over, GDP, fixed asset investment in agriculture, forestry, animal husbandry and fishery, and expenditure on agriculture, forestry and water affairs come from the
National Bureau of Statistics. Due to the large number of data sources, each database data has problems such as abnormal variable size and missing data to a certain extent. Therefore, the original data needs to be preprocessed. It can use the average replacement method to fill in the vacant values, and at the same time, use the form of multiplying the data by 100 and then taking the logarithm to remove the extreme values and smooth the data.

\subsection{Descriptive statistical analysis}

Descriptive statistics are performed on all variables used in this article, and the corresponding results are shown in Table 1. As shown in the figure, during the sample inspection period, there is a large gap between the maximum value and the minimum value of the agricultural industrial structure optimization index, indicating that there are significant differences in the upgrading of the agricultural industrial structure in various provinces. At the same time, in the natural logarithm of agricultural insurance density and agricultural insurance depth, there is a large difference between the maximum value and the minimum value, reflecting the uneven development level of agricultural insurance in various provinces, and the development of agricultural insurance varies significantly between provinces.

Table 1 Descriptive statistics for variables

\begin{tabular}{lllllll}
\hline Variables & \multicolumn{1}{c}{ Implication } & $\begin{array}{c}\text { Observed } \\
\text { value }\end{array}$ & Average & $\begin{array}{l}\text { Standard } \\
\text { deviation }\end{array}$ & Minimum & Maximum \\
\hline$y h$ & 309 & 3.651 & 0.945 & -1.294 & 5.600 \\
& $\begin{array}{l}\text { Optimization of } \\
\text { agricultural industrial } \\
\text { structure }\end{array}$ & & & & & \\
& $\begin{array}{l}\text { Agricultural insurance } \\
\text { density }\end{array}$ & 309 & 3.052 & 1.035 & -1.330 & 5.580 \\
dep & $\begin{array}{l}\text { Agricultural insurance } \\
\text { density }\end{array}$ & 310 & -0.417 & 0.990 & -4.157 & 2.076 \\
$f e e$ & $\begin{array}{l}\text { Fiscal expenditure on } \\
\text { agriculture }\end{array}$ & 310 & -1.051 & 1.802 & -2.673 & 16.515 \\
Gdp & $\begin{array}{l}\text { Level of economic } \\
\text { development }\end{array}$ & 309 & 9.604 & 1.012 & 6.240 & 11.590 \\
Urban & $\begin{array}{l}\text { Level of urbanization } \\
\text { Investment in agricultural }\end{array}$ & 310 & 4.000 & 0.244 & 3.121 & 4.495 \\
fixed assets & 310 & 5.885 & 1.325 & -0.434 & 8.323 \\
old & Ageing of rural population & 310 & 2.301 & 0.269 & 1.685 & 2.942 \\
\hline
\end{tabular}

\subsection{Possible problems and solutions in the model}

\subsubsection{Colinear problem}

In order to test the existence of multiple collinearity among variables, this paper analyzes the correlation between variables, and the results of the correlation coefficient matrix show that except fee and $g d p$ and old, $g d p$ have some correlation. The correlation coefficients of all other explanatory variables are below 0.4 . Therefore, there is no obvious collinearity problem in this paper. 
Table2 Correlation coefficient matrix for variables

\begin{tabular}{lllllllll}
\hline & $y h$ & $m d$ & dep & fee & gdp & urban & fix & old \\
\hline md & -0.0370 & 1.0000 & & & & & & \\
dep & 0.0298 & 0.8358 & 1.0000 & & & & & \\
fee & 0.0983 & 0.3390 & 0.3773 & 1.0000 & & & & \\
gdp & -0.0188 & -0.1209 & -0.1497 & -0.0823 & 1.0000 & & & \\
urban & 0.1505 & -0.2799 & -0.0058 & 0.0139 & 0.3850 & 1.0000 & & \\
fix & -0.1143 & 0.1501 & -0.2080 & -0.0679 & 0.4414 & -0.3058 & 1.0000 & \\
old & 0.1279 & -0.2703 & -0.3036 & -0.1095 & 0.7291 & 0.2802 & 0.2852 & 1.0000 \\
\hline
\end{tabular}

\subsubsection{Endogenous issues}

This article studies the impact of agricultural insurance development level on the upgrading and optimization of agricultural industrial structure. The endogenousness of the model mainly comes from omitted variables and reverse causality. Regarding the problem of missing variables, this paper adds important control variables that may have an impact on the agricultural industry structure in the regression, such as the level of economic development, the aging of the rural population, the fiscal expenditure on agriculture, agricultural fixed asset investment, and the level of urbanization. For the reverse causality problem, this paper uses the dynamic panel system GMM model to circumvent the endogenous problem to a certain extent.

\subsubsection{Robustness}

The influence of extreme value on the conclusion should be considered when considering the structure of agricultural industry. In the sixth part, the robustness is tested by sample regression.

\section{Empirical Analysis}

\subsection{Benchmark regression results}

Based on the systematic GMM, the relationship between the development level of agricultural insurance and the upgrading of agricultural industrial structure is regressed. Table 3 reports the regression results. Model (1) is the core explanatory variable $m d$ and model (2) is the core explanatory variable $d e p$. Model (3) is to add all control variables on the basis of model (1), model (4) is to add all control variables on the basis of model (2), adds core explanatory variables $m d$ and $d e p$ all control variables at the same time. From the various tests, the p-values corresponding to the $\mathrm{AR}(1)$ test in the model (1) to model (5) columns are 0.0171, 0.0232, 0.0151, 0.0232, and 0.021 , which are all less than 0.05 , and the $\operatorname{AR}(2)$ test corresponds to. The p-values of are $0.1095,0.1192$, $0.1081,0.1011$, and 0.1036 , which are all greater than 0.05 , indicating that at the $5 \%$ significance level, the disturbance terms in all models have first-order autocorrelation, but none of them have second-order autocorrelation. That is, all passed the serial correlation test. The p-values corresponding to the Sargan test of model (1) to model (5) are 0.9568, 0.5562, 1.0000, 0.9954 , and 1.0000, which are all greater than 0.05 , indicating that at the $5 \%$ significance level, the instrumental variables selected by these models. If they are valid, they all pass Sargan's test. The above inspection shows that the system GMM is valid.

From model (1) to model (5), it can be seen that the coefficients of the first-order lag term of the index of agricultural industrial structure advancement are all greater than 0.8 , and are significant at the $1 \%$ level. It shows that the advancement of the agricultural industrial structure in the previous period has significantly promoted the upgrading of the agricultural industrial structure in the current period, thus confirming the necessity of using the dynamic panel model for estimation.

The core explanatory variable agricultural insurance density in the five models all passed the test at the $1 \%$ level. The coefficient in model (5) is -2.69 , which shows that the increase in agricultural insurance density has a significant inhibitory effect on the upgrading of agricultural industry structure, which is not in line with the expected result, which may be caused by market failure caused by the nature of agricultural insurance itself as a quasi-public item. The underwriting enthusiasm of commercial insurance companies has been discouraged, and agricultural insurance can hardly play its role in safeguarding the upgrading of the industrial structure. At the same time, the large subsidies of agricultural insurance premiums will cause huge pressure on local finances, and the unity of the types of agricultural insurance underwriting targets also makes it impossible for regions to adjust the industrial structure according to local conditions. The core explanatory variable agricultural insurance depth in the five models all pass the test at the $1 \%$ level, and the coefficient in model (5) is 2.57, which shows that the increase in agricultural insurance depth has a significant positive role in promoting the upgrading of agricultural industrial structure. As one of the important tools for market-oriented agricultural risks, agricultural insurance uses various means before and after the event to help farmers avoid risks to the greatest extent, make up for their losses caused by the uncertainty of industrial structure adjustment, and improve the industrial structure and adjust the enthusiasm.

According to the benchmark model (5), for every $1 \%$ decrease in agricultural insurance density, the optimization level of the agricultural industry structure 
will increase by $0.586 \%$. For every $1 \%$ increase in the depth of agricultural insurance, the optimization level of the agricultural industry structure will increase by $0.586 \%$. With the continuous development of agricultural insurance, the upgrading and optimization of the agricultural industry structure will continue to advance. Among the control variables, the economic development level coefficient is -0.525 , which is significant at the $1 \%$ level, but it does not match the expected sign, which has a negative impact on the upgrading of the agricultural industry structure. It may be because the rapid economic development has to a certain extent caused the unreasonable distribution of resources among the rural areas, thus affecting the process of upgrading and optimizing the industrial structure. The aging coefficient of the rural population is 2.577 , and it is significant at the $1 \%$ level, indicating that aging has a significant role in promoting the upgrading of the agricultural industry structure. With the transfer of labor to non-agricultural industries, most of the current rural society engaged in agricultural production is the elderly and infirm. In order to solve the labor restrictions in agricultural production, more modern agricultural machinery and equipment and advanced technology will be purchased. This production method of substituting capital for labor promotes the deepening of agricultural production capital, and regional agricultural development will rely more on technology and capital, thereby accelerating the upgrading of the agricultural industrial structure. The urbanization level coefficient is 0.694 , and it is significant at the $10 \%$ level. Urbanization promotes the upgrading and optimization of the industrial structure by affecting the level of regional economic development and material capital. The agricultural fixed asset investment coefficient is 0.262 , and it is significant at the $1 \%$ level, indicating that the continuous increase in agricultural fixed asset investment has provided favorable material, capital, and human conditions for the optimization of the agricultural industry structure. The coefficient of fiscal expenditure on agricultural support is 0.0344 , which is significant at the $5 \%$ level in line with expectations, indicating that the investment of fiscal funds has a significant positive role in promoting the upgrading of the industrial structure.

Table3 Study on the impact of agricultural insurance on the upgrading of agricultural industrial structure

\begin{tabular}{|c|c|c|c|c|c|}
\hline Variables & (1) & (2) & (3) & (4) & (5) \\
\hline \multirow[t]{2}{*}{ L.y } & $0.625^{* * *}$ & $0.459^{* * *}$ & $0.669^{* * *}$ & $0.618^{* * *}$ & $0.586^{* * *}$ \\
\hline & $(41.75)$ & (122.91) & $(48.22)$ & (35.16) & $(22.31)$ \\
\hline \multirow[t]{2}{*}{$m d$} & $-0.168^{* * *}$ & & -0.0627 & & $-0.788^{* * *}$ \\
\hline & $(-7.41)$ & & $(-1.49)$ & & $(-2.69)$ \\
\hline \multirow[t]{2}{*}{ dep } & & $-0.228^{* * *}$ & & $-0.107^{* * *}$ & $0.752^{* *}$ \\
\hline & & $(-13.69)$ & & $(-2.59)$ & $(2.57)$ \\
\hline \multirow[t]{2}{*}{$g d p$} & & & $-0.661^{* * *}$ & $-0.583^{* * *}$ & $-0.525^{* * *}$ \\
\hline & & & $(-2.90)$ & $(-3.94)$ & $(-4.20)$ \\
\hline \multirow[t]{2}{*}{ old } & & & $2.928^{* * *}$ & $2.089^{* *}$ & $2.577^{* * *}$ \\
\hline & & & $(2.95)$ & $(2.22)$ & (3.17) \\
\hline \multirow[t]{2}{*}{ urban } & & & $0.923^{* * *}$ & $1.293^{* * *}$ & $0.694^{*}$ \\
\hline & & & $(3.44)$ & $(5.56)$ & (1.76) \\
\hline \multirow[t]{2}{*}{ inf } & & & $0.118^{* * *}$ & $0.176^{* * *}$ & $0.262^{* * *}$ \\
\hline & & & $(3.01)$ & $(6.91)$ & $(2.78)$ \\
\hline \multirow[t]{2}{*}{ infe } & & & $0.0332^{* * *}$ & $0.0289^{* * *}$ & $0.0344^{* *}$ \\
\hline & & & $(3.48)$ & $(3.74)$ & $(2.27)$ \\
\hline \multirow[t]{2}{*}{ _cons } & $1.900^{* * *}$ & $1.915^{* * *}$ & $-3.304^{* * *}$ & $-4.048^{* *}$ & -0.888 \\
\hline & (15.81) & $(269.43)$ & $(-2.74)$ & $(-2.47)$ & $(-0.61)$ \\
\hline$N$ & 278 & 277 & 278 & 277 & 277 \\
\hline$A R \_1$ & 0.0171 & 0.0232 & 0.0151 & 0.0232 & 0.021 \\
\hline$A R \_2$ & 0.1095 & 0.1192 & 0.1081 & 0.1101 & 0.1036 \\
\hline Sargan_p & 0.9568 & 0.5562 & 1.0000 & 0.9954 & 1.0000 \\
\hline
\end{tabular}

Note: (1) The corresponding t statistics are in parentheses. (2) L. represents a lag of one period for the variable. (3)*** and $* * *$ are significant at levels $0.1,0.05$ and 0.01, respectively. AR(1)、AR(2) and Sargan (p) are the p values obtained by the relevant tests respectively.

\subsection{Robustness test}

To enhance the empirical validity, this paper adopts the method of removing extreme values, removing the core explanatory variables agricultural insurance density (md) and the maximum and minimum values of agricultural insurance depth (dep). The sample value is changed from 31 to 29 , and the test is repeated. The impact of the development of agricultural insurance on the upgrading 
of China's agricultural industry structure. Table4 reports the robust regression results of agricultural insurance to the upgrading of agricultural industrial structure. Among them, model (1) is the regression result after removing the extreme value of agricultural insurance density (md). Model (2) is the regression result after removing the extreme value of agricultural insurance depth (dep). Model (3) is the result of full sample regression. It can be seen from the table that the sign $(+,-)$ and significance test of the impact of agricultural insurance development level on the upgrading of agricultural industrial structure are consistent with the previous benchmark estimation results (Table 3 ). It shows that during the sample period, the increase in agricultural insurance density will inhibit the upgrading of the agricultural industry structure, and the increase in the depth of agricultural insurance will promote the upgrading of the agricultural industry structure. Therefore, the test result is robust, and the regression result of agricultural insurance density is more robust than the depth of agricultural insurance.

Table 4 Robustness Test

\begin{tabular}{|c|c|c|c|}
\hline Variable & (1) & (2) & (3) \\
\hline \multirow[t]{2}{*}{ L.y } & $0.578^{* * *}$ & $0.564^{* * *}$ & $0.586^{* * *}$ \\
\hline & $(18.85)$ & $(9.87)$ & $(22.31)$ \\
\hline \multirow[t]{2}{*}{$m d$} & $-0.837^{* *}$ & $-0.945^{* *}$ & $-0.788^{* * *}$ \\
\hline & $(-2.37)$ & $(-2.36)$ & $(-2.69)$ \\
\hline \multirow[t]{2}{*}{$d e p$} & $0.732^{* *}$ & $0.840^{* *}$ & $0.752^{* *}$ \\
\hline & $(2.08)$ & $(2.15)$ & $(2.57)$ \\
\hline \multirow[t]{2}{*}{$g d p$} & $-0.302^{*}$ & -0.35 & $-0.525^{* * *}$ \\
\hline & $(-1.86)$ & $(-1.11)$ & $(-4.20)$ \\
\hline \multirow[t]{2}{*}{ old } & 1.306 & 1.657 & $2.577^{* * *}$ \\
\hline & $(1.35)$ & (1.03) & $(3.17)$ \\
\hline \multirow[t]{2}{*}{ urban } & 0.247 & 0.174 & $0.694^{*}$ \\
\hline & $(0.65)$ & $(0.36)$ & $(1.76)$ \\
\hline \multirow[t]{2}{*}{ inf } & $0.282^{* * *}$ & $0.262^{* * *}$ & $0.262^{* * *}$ \\
\hline & $(2.96)$ & $(2.81)$ & $(2.78)$ \\
\hline \multirow[t]{2}{*}{ infe } & $0.0470^{* * *}$ & $0.0385^{* *}$ & $0.0344^{* *}$ \\
\hline & $(2.73)$ & $(2.4)$ & $(2.27)$ \\
\hline \multirow[t]{2}{*}{ _cons } & 1.71 & 2.244 & -0.888 \\
\hline & $(1.11)$ & $(0.81$ & $(-0.61)$ \\
\hline$N$ & 259 & 260 & 277 \\
\hline$A R \_1$ & 0.0259 & 0.0266 & 0.021 \\
\hline$A R \_2$ & 0.1524 & 0.1061 & 0.1036 \\
\hline Sargan_p & 1 & 1 & 1.0000 \\
\hline
\end{tabular}

Note:(1) The corresponding t statistics are in parentheses. (2) L. represents a lag of one period for the variable. (3)*,** and *** are significant at levels $0.1,0.05$ and 0.01 , respectively. AR(1)、 $\mathrm{AR}(2)$ and Sargan (p) are the $\mathrm{p}$ values obtained by the relevant tests, respectively.

\subsection{Endogenous test}

This article uses two methods to control endogenity. One is to use more control variables, such as the level of economic development, the aging of the rural population, the level of urbanization, the level of agricultural fixed asset investment, and the fiscal expenditure on agricultural support. On the other hand, the article uses the panel data of 31 provinces and regions from 2010 to 2019 are regressed using the system GMM dynamic panel model to avoid the influence of reverse causality to a certain extent.

\section{Conclusions and recommendations}

\subsection{Research conclusion}

By using the provincial panel data from 2010-2019, this paper selects the multi-dimensional benchmark measurement model of dynamic panel model, and empirically analyzes the influence of agricultural insurance development level on the optimization of agricultural industrial structure upgrading. The main conclusions are as follows.

\subsubsection{The increase of agricultural insurance density inhibits the upgrading of agricultural industrial structure under certain conditions.}

From the perspective of the current agricultural insurance premium structure, about $80 \%$ of the share comes from the national, provincial, municipal and county-level finances. The fixed proportion of fiscal premium subsidies puts a lot of pressure on local finances, especially in the main grain-producing regions that were originally financially tight and impoverished counties. The lack of sufficient funds from the local government should be used to improve agricultural infrastructure, introduce new agricultural technologies, and other measures that directly upgrade the structure of the agricultural industry. The large premium subsidies of agricultural insurance are often only aimed at the planting and breeding industries in the large agricultural sector. As a rational economic man, most farmers will choose to plant or breed animals and plants that are heavily subsidized by agricultural insurance, which is not conducive to the adjustment of industrial structure in various regions according to local conditions. At the same time, agricultural insurance is a special commodity with high social benefits and low economic benefits. This feature of agricultural insurance determines that it belongs to quasi-public goods, not private goods, and the market mechanism cannot effectively provide such goods. As a result, market failures occurred, agricultural policy insurance was commissioned by commercial insurance companies, and the high loss rate resulted in low efficiency of agricultural insurance companies. Therefore, large agricultural insurance premium subsidies often deter commercial insurance companies from undertaking agricultural insurance. They often use farmers' 
inadequate understanding of insurance information to set up obstacles when making claims, and then achieve profit increments at the expense of the insured farmers' interests. In this way, agricultural insurance cannot play a good role in safeguarding the upgrading of the industrial structure, but will inhibit the upgrading and optimization of the agricultural industrial structure.

\subsubsection{The improvement of agricultural insurance depth has a significant role in promoting the upgrading of agricultural industrial structure.}

Although the increase in agricultural insurance density has some potential problems in the process of promoting the adjustment of the agricultural industry structure. However, according to the agricultural risk management theory and industrial structure upgrading theory, based on the results of empirical analysis, the increase in the depth of agricultural insurance still has a significant positive role in promoting the upgrading of agricultural industrial structure. Agricultural insurance is one of the important tools for agricultural risk management. Agricultural insurance companies use their expertise in disaster prevention and loss prevention in advance to help farmers implement effective agricultural risk prevention in advance and reduce the incidence of risks. At the same time, the training of farmers through professional insurance companies will be more conducive to them to master advanced agricultural production technology. At the same time, the risk diversification effect of agricultural insurance also promotes the increase of agricultural credit supply. After the incident, agricultural insurance can make up for the economic losses of the farmers through compensation, eliminating the worries of the farmers and restoring the enthusiasm of the farmers. Sufficient financial support and advanced production technology can enable farmers to continue to increase the level of agricultural scale and specialization, increase labor productivity, optimize the allocation of production factors among various industries, and promote the upgrading of the agricultural industry structure to capital-intensive and technology-intensive and realize the optimization of the industrial structure.

\subsection{Recommendations}

Based on the conclusion of this paper, in order to use the development of agricultural insurance to promote the development of agricultural economy in China, the following suggestions are put forward.

\subsubsection{Promote the diversified development of} agricultural insurance, attract more farmers to participate in agricultural insurance, and escort the upgrading of the agricultural industry structure.

The analysis in this paper proves that the increase in the depth of agricultural insurance has a significant positive role in promoting the upgrading of the agricultural industry structure. In addition to increasing the depth of agricultural insurance through fiscal subsidies and tax incentives, the coverage rate of agricultural insurance should also be improved by guiding the diversified development of agricultural insurance. Firstly, it can promote the diversification of agricultural insurance underwriting targets, so as to support agricultural intermediary service organizations and provide intermediary service support for the adjustment of agricultural industrial structure. Secondly, on the basis of drawing lessons from agricultural production insurance products, it can enrich and develop special insurance products for agricultural industrial restructuring to avoid the dilemma of farmers falling into the prisoner's dilemma to the greatest extent, and avoid farmers' troubles in the process of upgrading the agricultural industrial structure. Thirdly, scientific and reasonable underwriting, adapting measures to local conditions, and underwriting conditions are appropriately tilted to the focus of agricultural structural adjustment in different regions, and farmers in different regions are guided to plant crops that are more suitable for local ecological environment and economic development according to local conditions, so as to promote the increasingly rationalized agricultural industrial structure. Finally, it can develop various agricultural insurance products that respond to different risks in the upgrading of the agricultural industry structure, provide insurance types with different protection levels for the same crop insurance, and determine different levels of premium subsidy rates to continuously enrich and improve agricultural insurance that supports the upgrading of the agricultural industry structure. The product system better adapts to agricultural credit, agricultural technology diversification, and the protection needs of farmers at all levels, so that the role of agricultural insurance in upgrading the industrial structure can be more fully displayed.

\subsubsection{Establish the mechanism of agricultural risk reinsurance and disperse the risks in the adjustment of industrial structure, and provide a strong guarantee for the upgrading of agricultural industrial structure.}

Agricultural reinsurance can use the power of the market to resolve various risks in the adjustment of the agricultural industry structure and ensure that even in the event of a catastrophe, commercial insurance companies can obtain income that is not lower than the average social profit. The establishment of a unified national policy-based agricultural reinsurance company can maximize the national diversification of agricultural regional risks and increase the enthusiasm of commercial insurance companies to operate special insurance for agricultural industrial restructuring. It can encourage it to continuously innovate agricultural products, improve service and management levels, and ensure the supply of insurance related to industrial restructuring. To a certain extent, it can alleviate the imbalance between supply and demand in the agricultural insurance market, and strengthen the function of agricultural insurance to promote the upgrading of the industrial structure. The 
development of an agricultural risk reinsurance system requires strong support from the government, which is a huge project. Drawing on successful international experience, the development of a reinsurance mechanism can start from the formulation of relevant laws and regulations, the establishment of agricultural reinsurance companies and agricultural reinsurance funds, and the implementation of encouraging policies for the original insurers to guide them to participate in the reinsurance business.

\section{References}

1. Turvey C G. An Economic Analysis of Alternative Farm Revenue Insurance Policies[J]. Canadian Journal of Agricultural Economics, 1992, 40(3): 403-426.

2. $\mathrm{Wu} J$ J. Crop Insurance, Acreage Decisions, and Nonpoint-Source Pollution[J]. American Journal of Agricultural Economics, 1999, 81(2): 305-320.

3. Wu J J, Adams R M. Production Risks, Average Decisions and Implications for Revenue Insurance Programs[J]. Canadian Journal of Agricultural Economics, 2001, 49(1): 19-35.

4. Glauber J W, Collins K J. Crop Insurance, Disaster Assistance, and the Role of Federal Government in Providing Catastrophic Risk Protection[J]. Agricultural Finance Review, 2002, 62: 81-101

5. Coleman J A, Shaik S. Time-Varying Estimation of Crop Insurance Program in Altering North Dakota Farm Economic Structure[C]// 2009 Annual Meeting, July 26-28, 2009, Milwaukee, Wisconsin. Agricultural and Applied Economics Association, 2009.

6. Tronstad R, Bool R. U.S. Cotton Acreage Response Due to Subsidized Crop Insurance[C]// 2010 Annual Meeting, July 25-27, 2010, Denver, Colorado. Agricultural and Applied Economics Association, 2010.

7. Yu J, Smith A, Summer D A. Effects of Crop Insurance Premium Subsidies on Crop Acreage[J]. American Journal of Agricultural Economics, 2018, 100(1): 91-114.

8. Goodwin B K, Vandeveer M L, Deal J L. An Empirical Analysis of Acreage Effects of Participation in the Federal Crop Insurance Program[J]. American Journal of Agricultural Economics, 2004, 86(4): 1058-1077.

9. Young $\mathrm{C}$ E, Vandeveer M L, Schnepf $\mathrm{R}$ D. Production and Price Impacts of U.S. Crop Insurance Programs[J]. American Journal of Agricultural Economics, 2001, 83(5): 1196-1203.

10. Chen Juncong, Wang Huaming, Zhang Jin. The development of agricultural insurance and the growth of agricultural total factor productivity in
China [J]. Rural Economy, 2016(3) : 83-88.

11. Zhang Xiaodong, Sun Rong. Analysis on regional differences of agricultural insurance's impact on farmers' income based on cluster analysis of panel data [J]. Insurance Research,2015,(06):62-71.

12. Hao Aimin. The impact of producer services on agriculture - A study based on provincial panel data [J]. Finance and Trade Economics, 2011(7) : 97-102+136

13. Xie Xiaofeng. Research on the influence of agricultural producer services on agricultural production [D]. South China Agricultural University, 2016

14. Kuang Yuan-peng, Zhou Ling. Research on the effect of industrial structure of farmland transfer [J]. Economist,2016,(11):90-96. (in Chinese)

15. Xiong Yi. Research on the impact of agricultural insurance on the upgrading of agricultural industrial structure in China [D]. Huazhong Agricultural University,2020. 